\title{
Sports and the Culture of East Nusa Tenggara Society
}

\author{
Ary Moelyadi \\ Semarang State University \\ Semarang, Indonesia \\ emal: ary_moelyadi@yahoo.com
}

\begin{abstract}
Society of East Nusa Tenggara (NTT) has a good socio-cultural condition. This can be seen from the good social situation as well as their good social behavior of the people. That combination creates a conducive sociocultural condition. The culture as their characteristics differentiates them from other societies in other provinces. The purpose of this study is to describe the socio-cultural conditions in encouraging the delivery of the best athletes. The study used a phenomenological approach by interviewing several main figures who understand the development in NTT. It shows that the culture of NTT society is very influential in coaching and its development of sports. Cultural aspects must be well explored and developed to assist in the development of sports in NTT. It can be seen from prominent sports such as boxing and martial art that cannot be separated from the cultural background of the people of NTT.
\end{abstract}

Keywords: sports, culture, NTT society

\section{INTRODUCTION}

One aspect that influences the culture of people of NTT is the social conditions; their harmony and social order. The character of NTT people is tough; however, they are not easily provoked by the actions or incitement of certain parties [1]. Therefore, the social interaction of the NTT society in the socio-cultural aspect is relatively cooperative. This is indicated by the absence of conflicts that occur due to the activities of the society in the socio-cultural aspect. Thus, it shows that social harmony in NTT is considered very well. Meanwhile, the condition of social order in that province is also relatively good, based on statistical data, the total number of crimes has decreased significantly. Whereas, explained that social disease still haunts people in NTT. Therefore, every native is encouraged to create a sense of security from themselves, their families, and the local community.

The majority of NTT people are consumptive, they are not people who have a productive lifestyle. This explanation is based on the result of an empirical study published by the Central Bureau of Statistics of NTT Province. Nonetheless, the social behavior of NTT people is very good. This shows that the social behavior of the people is not easily influenced by something that comes from inside or outside the area.

Based on the description above, shows that the sociocultural condition of the people of NTT is relatively good. This is supported by the condition of social harmony and social behavior of the society which is very good and it is also supported by good conditions of both social order and social disease. Moreover, the factor of family condition that is also relatively good, so that it can create a fairly good socio-cultural condition. As a result, their culture becomes a distinct character that differentiates them from other societies in other provinces.

Then, how the people of NTT are interested in sports and how the coaching process is carried out up to now. This province has also a great potential in certain sports to reach the best achievements on the national and even international level.

Achievement achieved by athletes from NTT Province certainly cannot be separated from sports coaching conducted by coaches in the province. One of its social assets is culture. Even though NTT still experiences limitations in all aspects, the coaching and the development of sports that are carried out must ensure equitable access to sports, improvement of health and fitness, improvement of achievement, and management of sports in order to be able to face the challenges and the demand of change.

The coaching and development are held to produce outstanding athletes that cannot be instantly done. Therefore, it requires a long time and process which is carried out gradually, continuously, and systematically; moreover, it is also supported by the application of science and technology of sports. On the other hand, athletes' self-potential such as genetics, physiology, anatomy, psychological, and other scientific disciplines will also determine during the coaching process to reach optimal achievement. Support and role of environment, such as family, society, residence, supporting facilities and infrastructure, as well as adequate funds still need attention so that the process of coaching will run as expected.

Thus, the role of government especially on local government, sports organizations, coaches, sportsmen, and athletes, as well as parents and families have to provide support to all coaching processes. The human factor will be the main factor of expectation, goal, and targets to be achieved so that it is needed to do well planning and implementation through clear and definite standards during the entire process of sports coaching on short, medium, and long term programs. In addition, the synergy of the patterns and the coaching altogether and overall process with clear goals and targets are the keys to the achievement to be achieved by involving all majors and supporting elements so that all elements involved will have roles and responsibilities according to their capacity. On the other hand, trust and appreciation need to be given to every element involved in the coaching process and during the coaching process, starting from the lowest level, such as the level of sub-district, district, provincial, and central. It is because, in reality, everyone needs to be appreciated, so that the tasks given will be carried out based on their capacity and responsibility.

The representation of ideal sports coaching and development has been carried out by sports activists in NTT province, although it is still limited. The result of their coaching appears on 
international achievements in the branches of taekwondo and Kempo. However, the condition of NTT athletes to perform on the international level are rare and has continued to decrease since 2005 up to now.

Data achievement shows that achievement achieved by athletes from NTT begins in 1961 with the most excellent sport branches are athletics and boxing which are almost every year either for single or multi-event has always sent some representative athletes. The additional achievement in sports such as taekwondo and Kempo is inseparable from the socio-cultural environment that exists on the people of NTT who has tough character and always struggle to show their identity and prestige. Although they have limited infrastructure facilities, funds, resources of coaches, athletes, and sports personnel, they have a high spirit and enthusiasm in reaching hopes and goals, so that it becomes a pride for their families and regions.

Other factors that support the success of an athlete are family background, economic factor, social environment, culture, location of the school, geographical condition or topography of the athlete's residence and the most important factor is the personal or internal factor of the athlete. Those factors are very influential on the result of sports coaching there. However, since 2005 the achievements of NTT athletes have continued to decrease drastically. This phenomenon is the main attraction for the writer to conduct an analysis of the socio-economical culture of NTT society in supporting sports coaching programs in NTT province.

\section{A. Culture and Sports}

Before discussing the relationship between culture and sport, it is necessary to review culture. The term culture can be understood in several meanings [2]. Culture can refer to intellectual development, intelligence, and individual aesthetic, group or community. Culture also includes intellectual and artistic activities and the result, such as film, art, and theater which are used as the same as art. In another point, culture also shows the entire view of life, beliefs, and customs of people, groups, and societies.

Culture lives and develops in a variety of environments, one of them is in an organization of work, commonly known as culture. In reality, culture is very complex and has a deep element of the organizations that significantly impacts the members of an organization. Culture includes values, norms, beliefs, rituals, ceremonies, heroism, and bad people in the history of an organization. It has become a requirement regarding what new employees need to be accepted as members of the organization [3]. In another definition, it is described that culture is a pattern of shared basic assumption learned by groups to solve the problems of external adaptation and internal integration which are good enough and are considered valid, so that it is taught to new members the correct way to feel, think, and sense related to these problems [4].

Sports that developed in society cannot be separated from the cultural aspect. Sport is not situated in a space that has no value, social, and the context of politics; yet, it is influenced by all of those contexts [5]. It cannot be separated from the modern sports which include many aspects, they are (i) the ritual sacrifice of human energy; (ii) providing shared cultural currencies in the society; (iii) a means to compensate the deficiency in life; (iv) mechanism for affirming identity and difference; (v) business compared to sports; (vi) social product; (vii) arena of contestation formed by struggle both inside and outside the arena, (viii) be a euphemism for Western sports or capitalist [5].

The relationship between sport and society as well as culture as an integral part of the socio-cultural systems of a particular society causing the sports activities that exist in society to be different from sports activities in other societies. A sports activity is only a part of a series of human actions and behavior. The relationship between sports and culture, is on its place and society sports activities that will be distinguished based on population and cultural style [5]. The relation to culture or alienated culture from sports that has a different culture is influenced by their ethnicity or language.

The basic factor which influences an activity or sports action is the organic action of the human body; it is in the form of sociocultural systems [6]. This socio-cultural system is a series of knowledge models that exist on the various levels of human consciousness. Human uses these models selectively for their interests based on their goal compatibility that attracts their attention.

The province of NTT, which is rich in culture, has links to several sports branches indirectly, such as the Pasola culture that is a customary event on horseback and it is required to be skilled on carrying spears to be thrown each other. Therefore, the proses of talent scouting in the province of NTT should be adjusted to the island or area or region which has a cultural movement when the technological properties of the basic movement patterns are similar to the sports branches [7].

\section{RESEARCH METHODOLOGY}

A naturalistic phenomenological approach was used in this study. The phenomenon of phenomenology must be understood in broader meaning which deliberately covers all forms of appearance, demonstration, manifestation, showing evidence, testifies, disclosure of the truth, checking, and verification [8]. In the context of this study, phenomenology approach is used to study the condition of life, pattern, and behavior of NTT people viewed from the economic, social, and cultural aspects, especially on the coaches, sports personnel and athletes, parents, and the society in viewing coaching and sports development in NTT.

The extremely tough life in NTT has formed a strong mental and physical well-being of NTT people; as a result, it arises a strong struggling spirit on them. These conditions should be seen by sports coaches. Traditional games can also be used as the media to see the potential of children and to develop children's sports talent because sports coaching must be started earlier. One of the examples is a brisk walk athlete which is inseparable from the traditional games named water bearing on the childhood period because there are movements found in the brisk walk. As a result, it reinforces the Jariano concept related to the basic factor that influences the activity or action of sports, which is an organic action of the human body is in the form of socio-cultural 
see the potential of children and to develop children's sports talent because sports coaching must be started earlier. One of the examples is a brisk walk athlete which is inseparable from the traditional games named water-bearing during childhood because there are movements found in the brisk walk. As a result, it strengthens the Jariano concept related to the basic factor that influences the activity or action of sports, which is an organic action of the human body is in the form of socio-cultural systems. Thus, this finding shows that the development and the coaching of sports in NTT are relatively good and are in line with the existing concepts. The achievement achieved cannot be separated from the cooperation between the government, sports organization, and coaches in supporting athletes' facilities and other basic needs. Nevertheless, economic, social, and cultural factors influence the coaching and development of sports in NTT. However, evaluation is still needed as regards the training systems in other sports since there are only two sports that are seeded based on cultural factors in NTT.

\section{REFERENCES}

[1] Yuliawati, S. (2011). Pengukuran Gatra Sosial Budaya Di Provinsi Nusa Tenggara Timur. Jurnal Penelitian dan Evaluasi Pendidikan, 15(1), 139154.

[2] Smith, P. (2001). Cultural Theory: An Introduction. Malden: Blackwell Publishing.

[3] Champoux, JE (2011). Organizational Behavior: Integrating Individuals, Groups, and Organizations (4th ed.). New York: Routledge.

[4] Jarvie, G. (2006). Sport, Culture, and Society: An Introduction. Oxon: Routledge.

[5] Schein, EH (2010). Organizational Culture and Leadership (4th ed.). San Francisco: Jossey-Bass.

[6] Kostermans, Ding. "Peranan Olahraga Tradisional Terhadap Pelestarian Adat Dan Budaya." LEGALITAS 1, no. 1 (2017): 21-31.

[7] Lumba, J. F. A (2010). Analisis Gerak Budaya Pasola dan Berjalan Wanita Penjual Tuak dalam Mengidentifikasi cabang Olahraga di Provinsi Nusa Tenggara Timur. Universitas Negeri Surabaya.

[8] Moran, D., \& Mooney, T. (2002). The Phenomenology Reader. London: Routledge.

These conditions must be seen by sports coaches. Traditional games can also be used as the media to 